RAF medical officers at the RAF Club, London.

His packed schedule still allowed space to give valuable service to the Royal College of Psychiatrists. There he rose to the office of vice-president, as well as sitting on various important committees. Furthermore, in his time he served as President of the Section of Psychiatry of the Royal Society of Medicine.

He was a prolific writer: his publications included topics on eating disorders, carbon monoxide poisoning, panic disorders and sexual deviations. A particular interest in post-traumatic stress disorder was responsible for his concern with Rwanda, the unhappy country he visited frequently as a counsellor to the surviving victims of the appalling genocide.

No picture of Sydney Brandon is complete without mentioning his interests and hobbies. He enjoyed the thrill of driving fast cars, but above all he was a bon viveur: he loved good food and good wines in the company of his friends, of which I am proud to have been one. He had a passionate interest in the history of medicine as witness his valuable and extensive collection of medical artefacts.

His wife, Joanne, predeceased him, but he is survived by his two daughters and his devoted friends.

Henry R. Rollin

\section{Arumugam Sittampalam}

Formerly Consultant Forensic Psychiatrist, Broadmoor Hospital, Crowthorne, Berkshire

Arumugam Sittampalam died on 4 August 2001 after a stroke. Sitt, to his friends and colleagues, was born on 30 November 1922 in Jaffna, Sri Lanka. He qualified in 1949 at the University of Colombo, later obtaining the DPM, FRCP (Edin) and FRCPsych. From 1957-1971 he worked for the Ceylon Health Service as the senior psychiatrist. He left Sri Lanka in 1971 for Canada, where he was senior psychiatrist at the union hospital in Moose Jaw, Saskatchewan, but soon decided to come to the UK where he worked first from 1972-1979 as medical officer at HMP
Brixton and then from 1979 as a consultant forensic psychiatrist at Rampton Hospital. This meant that he was separated from his family, who were settled in London, so in 1981 he moved to Broadmoor where he worked until his retirement in 1992

Sitt was a quietly spoken, modest and intensely private man dedicated to his family. At Broadmoor his wide clinical experience, his diligence and his sound judgment were a tremendous asset and a stabilising influence, making him admired and respected by friends and colleagues of all disciplines. Towards the end of his time at Broadmoor he founded a dining club for doctors who had worked there, but disappointingly this did not long survive his retirement. At Broadmoor his generosity will long be remembered.

In the years following his retirement he spent his time with his grandchildren or gardening and watching sport. He leaves his wife, Puaneswary, and four sons and a daughter.

\section{David Tidmarsh}

\section{reviews}

\section{Cross-Cultural Psychiatry. A Practical Guide}

By Dinesh Bhugra and Kamaldeep Bhui. London: Arnold. 2001.

114 pp. $f 15.99$.

ISBN: 0-340-76379-5

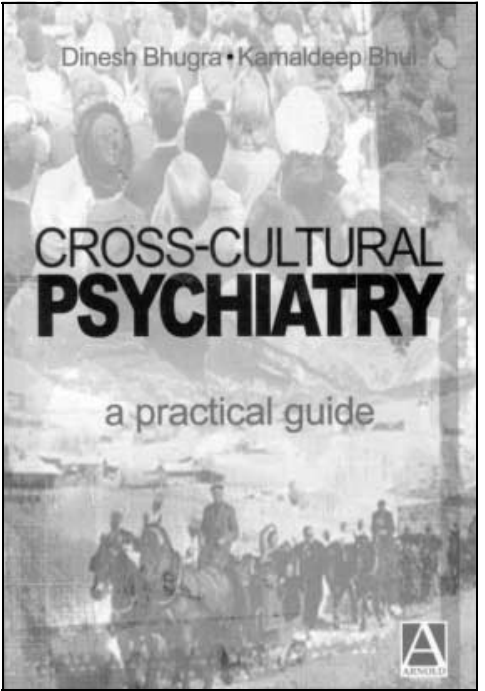

In this increasingly diverse country an understanding of cross-cultural issues in the practice of psychiatry has become essential. However, the literature is spread across a number of specialities including sociology, anthropology, history, political science and medical biology. It can be hard to find the information that you need and when you find it, it can be impenetrable. Because of this many clinicians may not develop the understanding of crosscultural issues that would be commensurate with good clinical practice.

Cross-Cultural Psychiatry. A Practical Guide aims to cut through this dense literature and offer some practical ways of understanding the challenges set by cross-cultural psychiatry. It is a jumpingon point, rather than a jumping-off point. It does not claim to be comprehensive but to 'open doors for clinicians and other health professionals to start thinking seriously about differences and similarities across cultures and individuals'.

The book is not targeted at specific cultural groups. General principles are considered more important than specifics. This parallels the position in the USA where cultural competence training offers transferable broad skills that help people understand cross-cultural interactions. It is assumed that this is the best way to cope with the fact that cultures develop and that over time new groups of people and new generations will present different challenges to psychiatrists. A psychiatrist will not be able to be 'culturally competent' for all groups and so to be a good psychiatrist he/she will need to develop common strategies for identifying cross-cultural problems and dealing with them.

The book is a good general introduction to the field and will become a 'must read' for all those in training or who are new to the field.

The book is not without problems. In my opinion the authors do not make it clear enough that the skills and strategies developed by the book are useful across the board - not just for ethnic minority groups. The reliance on UK ethnic minority groups for examples could lead the reader to believe that cross-cultural psychiatry refers to problems produced by an interaction between psychiatry and different ethnic groups, rather than the interaction of the cultural assumptions of psychiatric practice and different cultural groups. The majority of people in the UK somatise rather than psychologise their distress.

A further problem is that there is little discussion of the impact of discrimination or of institutional racism in this volume. It is important for individual clinicians to improve their clinical assessment and treatment, but improvements in care can be limited by institutional causes of disparities in service delivery. An understanding of this is required if clinicians are to be able to offer the best care for their patients.

Cross-cultural psychiatry is good psychiatry. Developing the knowledge base is fundamental to good practice. This short book is full of ideas and information and this is a good place to start.

Kwame McKenzie Royal Free and University College Medical School, London 